Rev Soc Esp Dolor

2015; 22(6): 281-282

\section{Analgesia en el politraumatizado obeso. Utilidad de la ketamina intravenosa fuera de quirófano}

\section{Sr. Director:}

Actualmente las opciones con las que cuenta el clínico para lograr la analgesia y sedación de un paciente obeso mórbido constituyen el objetivo de estudio de diferentes trabajos publicados (1). La discusión se centra en conseguir un efecto analgésico óptimo sin excesiva sedación y, sobre todo, lograr conservar la respiración espontánea y efectiva. Nuevos fármacos como la dexmedetomidina han logrado despertar gran interés porque se postulan como "no depresores de la respiración" y otros como las benzodiacepinas o los opiáceos se aconseja que deberían ser evitados. También se han evaluado en dichos artículos el propofol, los anestésicos volátiles, el remifentanilo, la ketamina, la lidocaína intravenosa o los alfa-agonistas (2).

En este trabajo evaluamos la utilidad de la ketamina intravenosa en un paciente politraumatizado y obeso para la analgesia y sedación fuera de quirófano.

Paciente de 27 años politraumatizado en un accidente de tráfico. Traumatismo costal múltiple y en hipocondrio izquierdo que ingresó en la unidad de cuidados críticos. Como antecedentes de interés destacaba obesidad mórbida (índice de masa corporal del 65\%). El paciente presentaba dolor, crepitación en hemitórax izquierdo y defensa a la palpación abdominal. En la tomografía axial computarizada de tórax y abdomen destacaba: "Hemoneumotórax izquierdo leve. Neumomediastino. Neumotórax derecho mínimo. Pequeños focos de contusión parenquimatosa y pequeña laceración pulmonar izquierda. Múltiples fracturas costales $\left(1 .^{\mathrm{a}}\right.$ a $10{ }^{\mathrm{a}}$ izquierdas y $1 .^{\mathrm{a}}$ derecha). Fractura de tercio medio de la clavícula izquierda. Enfisema subcutáneo cérvico-torácico izquierdo (Fig. 1). Rotura esplénica. Liquido libre intraabdominal leve."

Se instauró una perfusión continua de metamizol 12,5 $\mathrm{mg} / \mathrm{kg} / \mathrm{h}$ y ketamina (4 mcg $/ \mathrm{kg} / \mathrm{min}$ ) para control analgésico que permitió un control del dolor con EVA en torno a 3-4, sin efectos sobre la ventilación. El rescate analgésico consistió en bolos de morfina intravenosa administrados mediante PCA, registrándose una dosis máxima de $4 \mathrm{mg}$ durante las primeras 3 horas y posteriormente dosis inferiores a $0,2 \mathrm{mg} / \mathrm{kg} / 24 \mathrm{~h}$ (según peso ideal). Los valores de la gasometría arterial mostraron una presión parcial de oxígeno superior a 93 en todo el proceso. El paciente mejoró paulatinamente y fue dado de alta a hospitalización a los 7 días de su ingreso en cuidados críticos.

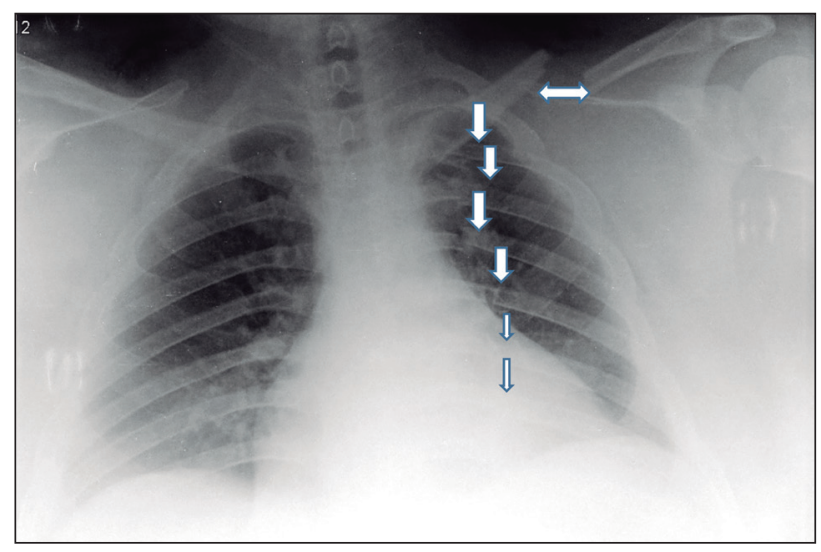

Fig. 1.

\section{Discusión}

Aproximadamente el 50\% de los pacientes ingresados en cuidados críticos tras politraumatismo recuerdan el dolor como su peor experiencia (3).

Los trabajos sobre la utilidad de la ketamina usada a dosis subanestésicas como analgésico son muy numerosos y su conclusión común es la efectividad de dicho fármaco unida a su seguridad. En concreto en el politraumatizado, la ketamina se ha propuesto recientemente como un fármaco muy seguro y se propugna, junto a otras drogas, como fármaco de elección en el ámbito extrahospitalario: ambulancias y primeros auxilios del accidentado (4).

En nuestro paciente se sumaban varios factores que obligaban a prestar mucha atención al control de la sedación y analgesia sin menoscabar la función respiratoria; la obesidad mórbida unida a la laceración del bazo, la fractura clavicular y el hemo-neumotórax nos hizo elegir utilizar analgesia intravenosa con bajas dosis de ketamina frente a técnicas loco-regionales como el bloqueo paravertebral o la epidural torácica y frente a otros fármacos como las benzodiacepinas, propofol, remifentanilo, etc. En la revisión de Choi de 2013 (5), se pone de manifiesto la importancia de evaluar bien cada caso y si es posible propone utilizar técnicas de bloqueo y analgesia regional pero se desaconseja su uso cuando se esté llevando a cabo la reanimación, haya riesgo de daño vascular o se requiera evaluación neurológica continua. También destacan la alta incidencia de infección y contaminación de catéteres para infusión continua de anestésicos locales en pacientes encamados (epidurales, nervios periféricos o paravertebrales). 
Tras consultar la bibliografía consideramos la opción de sumar dexmedetomidina pero no tuvimos disponibilidad de la misma. Otros fármacos como la lidocaína intravenosa también es una opción en estos pacientes; en nuestro paciente utilizamos cloruro mórfico en bolos intravenosos mediante PCA pero su uso fue mínimo (dosis máximas coincidiendo con las curas y cambios posturales) y el resultado obtenido fue satisfactorio.

M.A Rodríguez-Navarro, D. Rastrollo Peña, C. Díaz-Alejo, L. Sánchez y A.B. Alcaraz Martínez

Servicio de Anestesiología, Reanimación y Terapia del Dolor. Hospital General Universitario José M. ${ }^{a}$ Morales Meseguer. Murcia

\section{Bibliografía}

1. Aanta R, Tonner P, Conti G, Longrois D, Mantz J, Mulier JP. Sedation options for the morbidity obese intensive care unit patient: A concise survey and an agenda for development. Multidiscip Respir Med 2015;10(1):8.

2. Parashchanka A, Schelfout S, Coppens M. Role of novel drugs in sedation outside the operating room: Dexmedetomidina, ketamine and remifentanil. Curr Opin Anaesthesiol 2014;27(4):442-7.

3. Albrecht E, Taffe P, Yersin B, Schoettker P, Decostered I, Hugli O. Undertreatment of acute pain (oligoanalgesia) and medical practice variation in prehospital analgesia of adult trauma patients: A $10 \mathrm{yr}$ retrospective study. Br J Anaesth 2012;110(1):96-106.

4. Wiel E, Zitouni D, Assez N, Sebilleau Q, Lys S, Mauriaucourt $\mathrm{P}$, et al. Continuous infusion of ketamine for out-of-hospital isolated orthopedic injuries secondary to trauma: a randomized controlled trial. Prehosp Emerg Care 2014;18: 254.

5. Choi JJ, Lin E, Gadsen J. Regional anesthesia for trauma outside the operating theatre. Curr Opin Anesthesiol 2013;26:495-500. 